\title{
Mining Restaurant Data to Assess Contributions and Margins Data
}

\author{
Dr. Harikumar Pallathadka \\ Professor and Director, Manipur International University, Imphal, Manipur, India \\ harikumar@miu.edu.in \\ orcid.org/0000-0002-0705-9035
}

\begin{tabular}{|c|c|}
\hline Article History & Abstract \\
\hline $\begin{array}{l}\text { Article Submission } \\
21 \text { April } 2021 \\
\text { Revised Submission } \\
18 \text { June } 2021 \\
\text { Article Accepted } \\
22 \text { July } 2021 \\
\text { Article Published } \\
30 \text { September } 2021\end{array}$ & $\begin{array}{l}\text { The proposed business project seeks to ensure that at Monroe College's Bronx Campus, } \\
\text { the Jag Cafe emerges as a moderately priced restaurant offering convenience and } \\
\text { promising breakfast and lunch experiences for students, faculty, and other individuals } \\
\text { both in the campus community and in the neighborhood. Particularly, the proposed } \\
\text { project involves the adoption and implementation of a new menu aimed at achieving } \\
\text { family style services, food, and beverages. The proposal comes at a time when the } \\
\text { cafeteria's current menu is long and proves inconvenient in relation to the rate of order } \\
\text { turnover. The location of the project is Kings Hall. Indeed, some of the anticipated and } \\
\text { unexpected costs predicted to come with the new menu include the need to train } \\
\text { employees and also ensure that several materials are in place to accommodate the new } \\
\text { menu, and also ensure that the required raw materials and food preparation facilities } \\
\text { are in place. However, the three-year sales project suggests that the financial benefits } \\
\text { that might accrue from this project's implementation are likely to outweigh the } \\
\text { perceived costs. As such, the project is worth supporting because it not only promises } \\
\text { profitability but also strives to make the Jag Café a place with quality meals at } \\
\text { reasonable prices in the Bronx, as well as evolve as a home-style cafeteria in the } \\
\text { campus. } \\
\text { Keywords: Data Mining, Project Management }\end{array}$ \\
\hline
\end{tabular}

\section{Introduction}

A menu entails a list of beverages and food that customers receive in a restaurant, cafeteria, or food outlet, as well as the accompanying prices of the respective products and services that the institution offers. In school settings, the quality of the lunch that students receive has been correlated with academic performance. Particularly, Boek, Bianco-Simeral, Chan and Goto (2012) stated that there is a positive relationship between diet and cognitive function, as well as diet and cognitive development. In situations where schools offer quality lunches, El-Said and Fathy (2015) documented that there is likely to be better academic performance among students. In another investigation, Ibrahim, Mustapha and Saber et al. (2018) found that the provision of healthier school lunches reduces the risk for overweight among students. As concurred by Lee, Fowler and Yuan (2013), the trickle-down effect is that due to healthier school lunches, which reduce possibilities of health complications, academic performance improves in relation to reduced rates of absenteeism, as well as concentration among learners.

The proposed business project involves the development of a school cafeteria menu. The target institution in which the project is to be implemented is Monroe College, Bronx Campus. Several reasons account for the need to consider the proposed business project, especially regarding the projected benefits that it might offer to the college. For instance, the menu aims at meeting the school's policy of universal meal service provision, especially through nutritional balance with various dishes; eventually meeting the expectations of the campus community which will be assessed via regular feedback provision and service user research. Also, the proposed project is worth considering because it strives to support Bronx Campus' strategic aim of promoting community well-being, 
especially by working with various stakeholders to promote healthy lifestyles (and reduce health inequalities among students and other facility users). Furthermore, the feasibility of the project lies in its capacity to enhance and improve the dining experience of the college community - while maximizing meal uptake in the student community.

\section{Methodology}

Committed towards the realization of culinary excellence, Monroe College strives to offer its community with a go-to and healthy option, especially through its chefs. Regarding the meal plans, students have the option of selecting semester-long meal arrangements. Whereas the "Blue" meal plan involves 12 meals each week, the "Gold" meal plan allows the students to have 20 meals each week. Should a student opt for either arrangement, they can have their meals in New Rochelle or Bronx dining halls. Also, dinner, lunch, and breakfast could be enjoyed at Gaddy Café. With late-night dining options also available, some of the selections available include salads, pasta, and pizza.

To meet the entire college community's needs, Monroe College tailors dining venues, services, and programs. The culinary community also encourages feedback and communication through an open-door policy, comment boards, focus groups, and customer satisfaction surveys. Relative to the kitchen menu, factors considered include healthy, ethnic, and seasonal options. Specific provisions include holiday favorites (such as meatless holidays (that feature fresh fish), Saint Patrick's Day Corned Beef, and thanksgiving carved turkey), local foods, international foods (including Latin, Asian and Middle Eastern cuisine flavors), and local and celebrity-inspired specialties (Mensah and Mensah, 2018).

Indeed, qualities of a good menu include evidence of a coherent theme, appropriate pricing of the dishes, and a balancing act that neither offers too few or too many menu items (Lee, Fowler \& Yuan, 2013). From the figure above, Bronx Jag Café has a large menu, with numerous dishes making it challenging to achieve the attribute of quality. A large number of items on the cafeteria's menu implies further that the institution requires a lot of ingredients, which attracts the dilemma of cost-effectiveness in relation to its current menu. Whereas it is easily readable, the menu is so large that it often requires more time spent on the production of orders. With each table taking longer to serve, a secondary effect of the five-page menu is that it has ended up slowing the rate of order turn over, translating into a lack of focus. The additional problem is that week after week, most of the meals are repeated (El-Said \& Fathy, 2015).

To address the menu-related problems facing the current state of the Jag Café, a literature survey is conducted based on company reports from other colleges, as well as some of the journals documented by previous scholarly investigations - regarding ideal menus that are customer-centered and seek to minimize the cost of production or service provision while maximizing the returns.

\section{Results and Discussion}

The proposed business project involves design and implementation of a new menu that seeks to be built around popular items in the Bronx. Some of the initial considerations will include through staff training, annual price updates, cleanliness, the use of creative texts and photos, and the grouping of the majority of profitable items together. Notable, the Jag, which is located in King Hall, is the target location and reflects a spacious and comfortable cafeteria. The map below illustrates the location of King Hall relative to the rest of the facilities at the campus. 


\section{MONROECOLLEGE Bronx Campus \& Area Map}

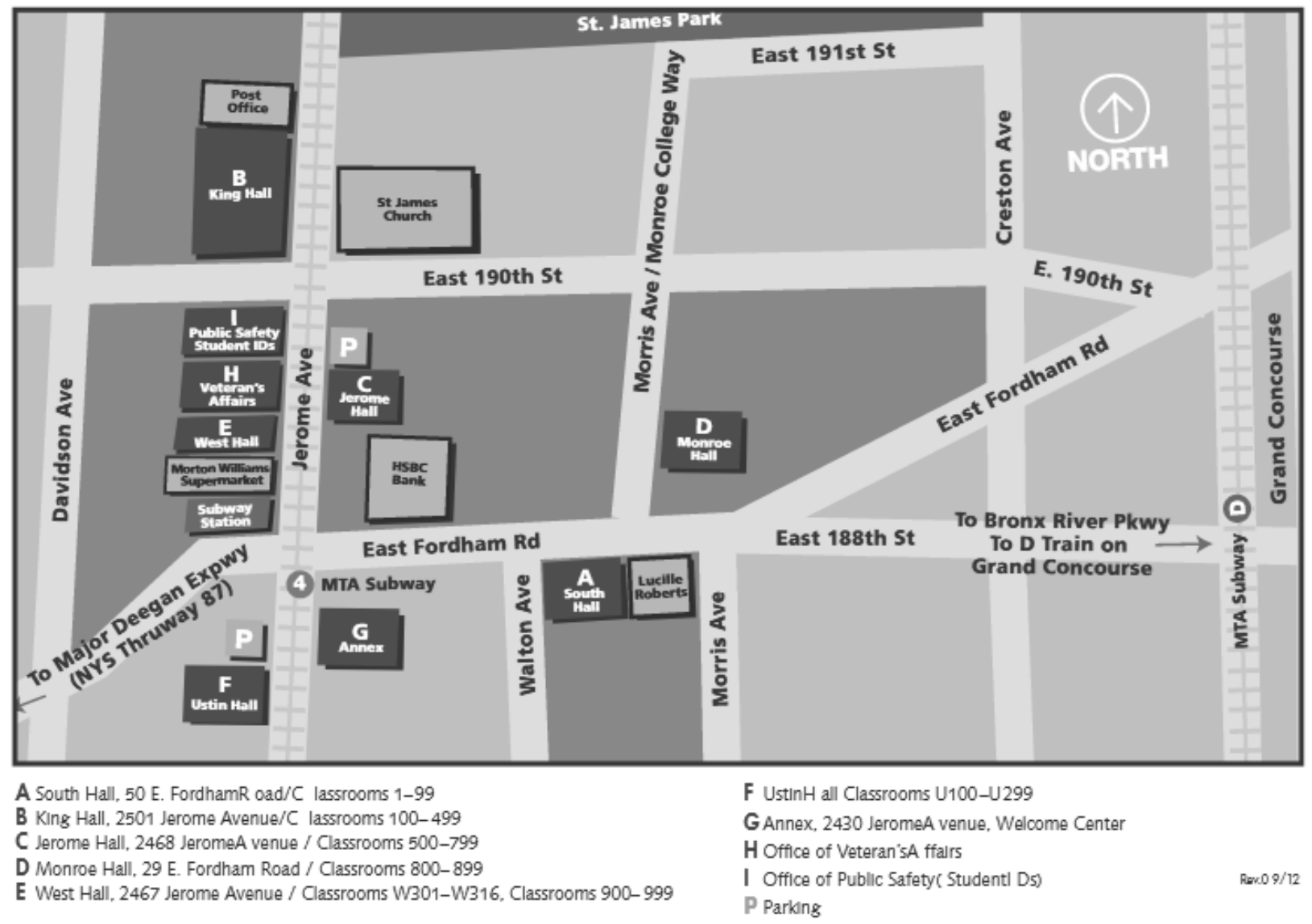

Figure 1. MONROE COLLEGE Area Map

The selected site constitutes a storage room, bathrooms, a kitchen, and a dining section. In response to the proposed menu, it will be expected that the kitchen is well equipped with small commercial dishwashers, a microwave, an oven, a walk-in-cooler, a freezer, refrigerator, and a commercial stove. The equipment above is expected to cost about 21,000 U.S. dollars. However, the design of the facility in preparation for the accommodation of the new menu will be done through a customer-built approach. Additional materials and processes expected to add to the start-up expenses include marketing, food inventory, and dishes. Targeting a basic American-style lunch and breakfast, the proposed project involving the development and implement of a new menu at the Jag Café will emphasize tasty and healthy foods. In a few cases, low-fat recipes will be applied, including situations where it will be important to curb against sacrificing appeal and taste.

Relative to the pricing issue, the new menu will be designed in such a way that breakfast will cost about $\$ 2$ to $\$ 5$. On the other hand, the lunch that the menu will reflect will have its price range between $\$ 3$ and $\$ 6$. Furthermore, the menu will accommodate daily specials and soups, with the hours of operation ranging from 6:30 a.m. to 3:00 p.m. these hours of operation will be from Monday to Saturday. On Sundays, the proposed menu will be implemented between 8 am and $4 \mathrm{pm}$. The staff to implement the menu will include waitresses, cooks, and a head cook. Another notable feature is that magazines and free books will supplement the new menu offerings, allowing customers to read inside the Jag Café.

According to Boek, Bianco-Simeral, Chan and Goto (2012), one of the growing trends involves eating out. In a college context, El-Said and Fathy (2015) stated that most of the community members are pressed for time, 
making this option convenient. In these environments, additional affirmations hold that lunch and breakfast are popular because most of the workers and students opt for "brown bag" menu offerings. In the wake of increasing cases of sedentary lifestyles, preparing a menu for the Jag Café implies that one of the major concerns involves the choice of low-fat, healthy food. With the current menu, which is long, proving ambivalent about the latter trends and concerns, the proposed business project seeks to realize a menu aimed at removing most of the unhealthy fat.

Indeed, marketing will be key to success through the maximization of high-margin product sales, as well as the realization of a loyal and solid customer base. As such, about 3,000 flyers will be distributed within the Bronx Campus, as well as its adjacent neighborhood. Other target areas where the flyers will be distributed include selected office buildings and at the shopping malls in the neighborhood. To ensure the visibility of a basic American-style lunch and breakfast among students and the rest of the community within and around Bronx Campus, printouts of free postcards endorsing this culture will also be distributed. According to El-Said and Fathy (2015), this marketing strategy ensures that restaurants cement the presence and loyalty of the target customer bases on campuses.

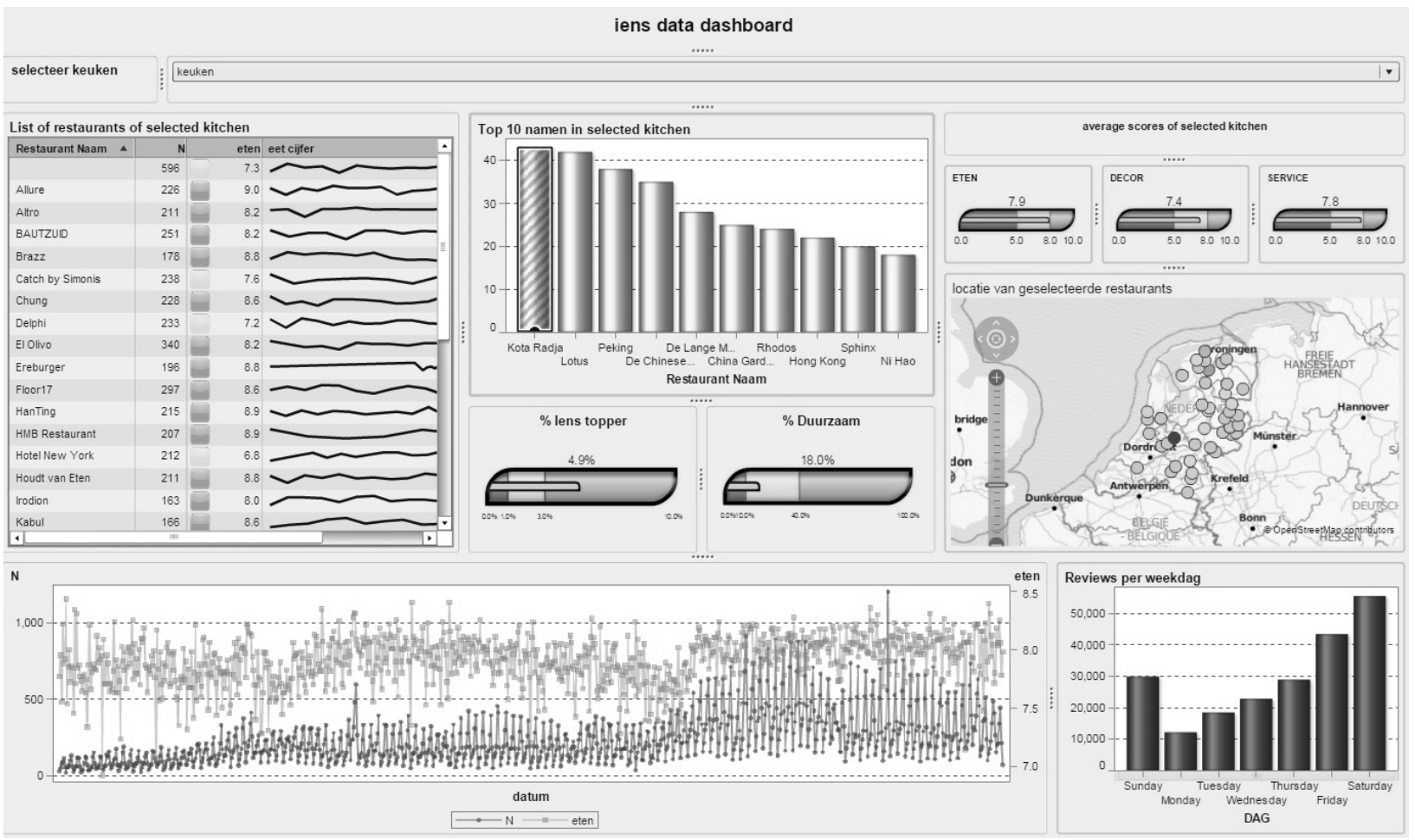

Figure 2. Lens Data Dashboard Analysis

The proposed project seeks to satisfy the needs of faculty and students at Bronx Campus, as well as individuals working in offices near the institution. From the recent market research by Lee, Fowler and Yuan (2013), these customer groups prefer the basic American-style lunch and breakfast. Also, the menu seeks to appeal to individuals with different categories of income, with the location within Monroe College's Bronx Campus assuring access to the intended customer base. The proposed project's market segmentation strategy holds further that most of the college students tend to gravitate towards better and tasty foods, observations that concur with market research by Mensah and Mensah (2018). Also, Boek, Bianco-Simeral, Chan and Goto (2012) stated that many college students perceive and prefer cafeterias as convenient meeting or studying locations from which they can interact with the rest of their peers without incurring cover charges. Therefore, the new menu is poised to yield a local client base in the Bronx Campus.

The new menu seeks to retain the current customers at the Jag Café while attracting new customers. Also, the objective is to ensure that the community at Bronx Campus comes back often and spends more. Apart from the 
provision of favorable referrals, the menu seeks further to generate more sales at the cafeteria. The sales strategy will operate in such a way that one employee will handle sales transactions while another will prepare the orders placed by customers. Also, client service will be offered by at least three employees; an approach projected to speed up the provision of customer services at the cafeteria.

The marketing program is set in such a way that the database clients, who constitute faculty and students, will be contacted and notified of the new menu at the Jag Café. Later, birthday and loyalty club members will receive information regarding special menu item offerings. As avowed by El-Said and Fathy (2015), birthday or loyalty programs such as those that involve the provision of chicken sandwich or complimentary hamburger or wraps for birthday persons yield repeat businesses, whose benefits are as high as 15 percent increase in revenues. Similarly, rapport will be developed with the rest of local businesses to make the Jag Café a healthy and quick lunch choice. Later, marketing campaigns will be held to ensure that within the market area, local businesses are called and that samples are delivered while encouraging the customer base to consider the café as a dining platform of choice. Superior customer service will also be emphasized and complement the home-style meals. With the new menu, employees will be trained about how to handle the complaints of customers, customer perception, and service attitudes. Also, there will be periodic staff meetings to review the new menu's progress, especially by acknowledging and responding to any guest complaints.

Notably, the proposed menu seeks to respond to recent restaurant and dining trends, especially in American colleges. According to Boek, Bianco-Simeral, Chan and Goto (2012), some of the trends that are worth considering include farm brand ingredients, back to basics cuisine, gluten-free allergy conscious menu offerings, sustainable seafood, and hyper-local food items. Others include nutritious dishes, sustainability as a key culinary theme, locally grown produce, and locally sourced seafood and meats (Mensah and Mensah, 2018).

Upon implementing the proposed business project, which comes in the form of a new and shorter but precise menu for the Jag Café, a major benefit that the facility is poised to experience involves an increase in sales, hence overall revenue. However, several costs are expected to arise and, should a keen operation be lacking, might threaten the projected profitability. Some of these costs include permits and licenses for the new menu, payroll taxes, miscellaneous expenses, credit card fees, shrinkage, and bad debts. Others include wages and salaries. Regarding the unexpected consequences, some of the issues that might arise include employee resistance to change, possible turnover due to ideological differences regarding the existing menu at the Jag Café, and the need for vibrant marketing activities, which call for additional expenses to sell the new menu and also cement the Jag Café's presence in Monroe College's Bronx Campus and its neighborhood.

\section{Conclusion}

After busy schedules, good food ensures that guests have an enjoyable experience. However, the menu plays an important role because it communicates menu planning is important because a good menu, which is at the heart of all food service operations, drives the sales, hence revenue and profitability. In this paper, a business project has been proposed. The business project involves the implementation of a new menu for the Jag Café at Monroe College, Bronx Campus. From the proposed project, the menu is worth adopting and implementing because of three major reasons. Firstly, it is poised to enable managers at the Jag Café to decide the type of cafeteria they project to run. Secondly, the proposed business is worth supporting because it might enable major stakeholders at the facility to determine who their customers or guests are. Thirdly, this project is worth supporting and funding because it will enable the managers at the Jag Café to discern the facility's operation's capability. It is also worth indicating that the proposed project comes with costs due to the need to train employees and also ensure that several materials are in place to accommodate the new menu, and also ensure that the required raw materials and food preparation facilities are in place. However, the three-year sales projection suggests that at the Jag Café, revenue benefits that might accrue from the adoption and implementation of the new menu are likely to outweigh the perceived costs; whether expected or unexpected. With profitability and satisfactory customer experience being some of the intended goals of a business facility, the Jag Café inclusive, the need to adopt and implement this project cannot be overstated. 


\section{References}

[1] Boek, S., Bianco-Simeral, S., Chan, K., \& Goto, K. (2012). Gender and race are significant determinants of students' food choices on a college campus. Journal of Nutrition Education \& Behavior, 44(4), 372-378

[2] El-Said, O. A., \& Fathy, E. A. (2015). Assessing university students' satisfaction with on-campus cafeteria services. Tourism Management Perspectives, 16, 318-324

[3] Ibrahim, M. Z. F., Mustapha, R. I. P. R., Saber, J. M., Jasni, W. N. F. W., \& Mehat, N. H. (2018). A Study on Student's Satisfaction towards On-Campus Foodservice: A Case of UITM Penang Students. International Journal of Academic Research in Business and Social Sciences, 8(17), 227-237

[4] Lee, S., Fowler, D., \& Yuan, J. (2013). Characteristics of healthy foods as perceived by college students utilizing university foodservice. Journal of Foodservice Business Research, 16(2), 169-182

[5] Mensah, I. and Mensah, R.D. (2018). Effects of Service Quality and Customer Satisfaction on Repurchase Intention in Restaurants on University of Cape Coast Campus. Journal of Tourism, Heritage \& Services Marketing, 4(1), 27-36 